\title{
Bioremediation of toluene by bioaugmentation, biostimulation and natural attenuation
}

\author{
Cevat Yaman ${ }^{1}$, Ismail Anil ${ }^{1}$, Omer Aga ${ }^{1}$, Ayse B. Yaman ${ }^{1}$, and Aleem Qureshi ${ }^{1}$ \\ ${ }^{1}$ Imam Abdulrahman Bin Faisal University, Environmental Engineering Department, 19082, Dammam, Saudi Arabia
}

\begin{abstract}
Contamination in subsurface environment is a serious environmental hazard. Main sources of the contamination are petrol, diesel fuel, gasoline at oil refineries, underground storage tanks, transmission pipelines and different industries. Permeable reactive barriers (PRBs), which is a promising technology to remediate groundwater in-situ, are filled with reactive materials for the removal of the contaminants present in groundwater. In this study, groundwater contaminated with toluene is treated in reactor columns by biological processes. This study was conducted to assess the impact of bioaugmentation (BA) and biostimulation (BS) on toluene degradation efficiency. After 44 days of treatment, toluene concentrations were decreased from $5 \mathrm{mg} / 1$ to $4.304 \mathrm{mg} / \mathrm{l}$ by the natural attenuation treatment (Reactor 2), which represents a $13.9 \%$ removal efficiency. Toluene was reduced to $0.0239 \mathrm{mg} / \mathrm{l}$ in the biostimulation and bioaugmentation treatment (Reactor 1), which represents a toluene removal efficiency of $99.5 \%$. This study showed that the toluene removal efficiency in the combined BA and BS process was much higher than in natural attenuation (NA) process tested.
\end{abstract}

\section{Introduction}

Contamination in subsurface environment has become a serious environmental hazard in recent years. Main sources of the contamination are petrol, diesel fuel, gasoline at oil refineries, underground storage tanks, transmission pipelines and non-petroleum related industries. These hazardous contaminants are in the EPA's (U.S. Environmental Protection Agency) priority pollutant lists. Besides, some of that chemicals in the fossil fuels tend to persist in the environment for a long time. These persistent contaminants have several health risks to humans, animals, and other living organisms. Therefore, this threat needs to be removed carefully from the subsurface environment. Removal of contaminants, especially petroleum hydrocarbons, from soil and groundwater through bioremediation technologies has been commonly practiced by researchers and industry. One of the most common remediation technologies is bioremediation which uses microorganisms to biodegrade hydrocarbon. Bioremediation has been commonly used for cleaning up soil and groundwater contaminated sites and is an environmentally friendly and cost-effective remediation technology.

Total petroleum hydrocarbons consist of three components: aliphatic (or saturated), aromatic, and polar hydrocarbon fractions. Diesel fuels primarily contain a mixture of $\mathrm{C} 10$ through $\mathrm{C} 19$ hydrocarbons, which include $64 \%$ aliphatic hydrocarbons, $1-2 \%$ olefinic hydrocarbons, and $35 \%$ aromatic hydrocarbons. All the above fuel oils contain less than $5 \%$ polycyclic aromatic hydrocarbons (PAHs). Biodegradation of petroleum hydrocarbons by microorganisms have been studied by scientists for many years. Microorganisms responsible for degrading crude and refined petroleum products are defined as either eukaryotic or prokaryotic organisms. Some of the species that are effective on biodegradation of petroleum hydrocarbons are Nocardia, Pseudomonas, Acinetobacter, Flavobacterium, Arthrobacter, Achromobacter, Alcaligenes, Mycobacterium, Bacillus, Aspergillus, Fusarium, Penicillium, and Sporobolomyces. Bioremediation method can be selected based on the properties of the polluting hydrocarbons and the characteristics of soil and the groundwater where the contaminant is spilled. It is preferred that the hydrocarbons contain carbon chain length of between $\mathrm{C} 10$ and $\mathrm{C} 20$, because these carbon chains are easier to break. On the other hand, hydrocarbons with $\mathrm{C} 20-\mathrm{C} 40$ carbon chains are hydrophobic, less soluble in water and resistant to biodegradation. Bioremediation is a technology that aims at cleaning a contaminated region by microorganisms and their enzymes. Specific contaminants such as chlorine containing pesticides can be also biodegraded by microorganisms. Microorganisms that degrade these hydrocarbons can be bacteria, protozoa, nematodes, and fungi. Bioremediation of a contaminated site by adding specifically selected microorganisms is called bioaugmentation.

Bioaugmentation technology is used effectively in soils and groundwater where there is not sufficient microbial population available for biodegradation. Bioremediation of a contaminated site by adding nutrients is called biostimulation. Some of the benefits of bioremediation can be summarized as; effective,

\footnotetext{
* Corresponding author: cyaman@iau.edu.sa
} 
economic, environment friendly, less toxic byproducts, applicable directly on the contaminated area and friendly with the existing flora.

When hydrocarbon-containing contaminants spill on land, degradation by indigenous microorganisms progresses slowly due to low microbial population and activity. Bioremediation is recognized as one of the most cost-effective clean-up methods for the treatment of oilcontaminated soils and groundwater. For instance, bioaugmentation (BA) and biostimulation (BS) are the two main bioremediation technologies commonly used for soil and groundwater clean-up. Bioaugmentation works by introduction of exogenous microorganisms to the contaminated soil or water. Microorganisms may be inoculated with specially cultivated microorganisms with capabilities for degrading a certain contaminant. Biostimulation is used to describe the addition of nutrients, such as nitrogen and phosphorus, to stimulate the existing microorganisms that are capable of degrading contaminants. On the other hand, natural attenuation (NA) processes can include chemical reactions, volatilization, adsorption, and biodegradation.

Bioremediation is the process of using microorganisms to convert organic compounds such as crude oil into non-toxic substances such as $\mathrm{CO}_{2}$ and $\mathrm{H}_{2} \mathrm{O}$. Any given bacteria can occur naturally and require specialized nutrients. In most cases naturally occurring microorganisms are not in sufficient concentrations to provide complete degradation. Thus, there exists an opportunity to enhance and accelerate the natural degradation by the introduction of additional microorganisms and nutrients. When mixed with water and applied as a slurry to contaminated soil or groundwater, microorganisms break down the molecular structures of the targeted hydrocarbons by utilizing their mass as a source of energy. Because of the high degree of interface between bacteria and the hydrocarbon, the rate of degradation tends to be quite rapid at first, but gradually diminishes as the more biodegradable hydrocarbon is consumed.

One of the most promising technologies for in-situ groundwater treatment is to use Permeable reactive barriers (PRBs). PRBs are filled with reactive materials and they must be permeable than the surrounding aquifer material. When compared to conventional pump and treat systems, PRB method is much cheaper because there is no continuous energy input is needed. The other benefit of PRBs is that replacement of the PRB material is always possible [1]. There are two types of PRBs, continuous PRBs and funnel and gate system PRBs. Continuous PRBs consist of a single reactive zone whereas funnel and gate PRBs consists of permeable gate (reactive zone) placed between two impermeable walls that direct the contaminated plume towards the reactive zone. The mechanisms of interaction in PRBs are degradation, precipitation and sorption. The types of reactive materials used in PRBs are those changing $\mathrm{pH}$ or redox potential, causing precipitation, materials with high sorption capacity, and releasing nutrients and oxygen to enhance degradation. Some of the reactive materials used in PRBs are activated carbon (AC), Al, ferric oxide, peat, zeolite, lignite, zero valent metals, fly ash, lime, limestone, sand, and clay.

PRBs consisting of zero valent iron (ZVI) can also be used to treat groundwater contaminated with chlorinated solvents, nitrate, chromium, uranium, and pesticides [2]. In another study, PRB columns filled with olive nut, sand and soil were usefully used to treat wastewater containing nitrate [3]. PAHs were successfully removed from water by using PRB materials of wheat straw and coconut shell [4]. Corn straw, fly ash, Fe-Mn, and zeolite were used as $\mathrm{PRB}$ materials to reduce the concentrations of $\mathrm{Pb}$ and $\mathrm{Cd}$ from groundwater [5]. Steel manufacturing basic oxygen furnace sludge (BOFS) was tested as a PRB material to remove $\mathrm{Cr}+6$ from soil [6]. Two lab scale column studies used ZVI and ZVI + zeolite to treat leachate [7]. In one study, ZVI, zeolite and activated carbon were used as PRBs to treat groundwater contaminated with leachate [8].

Toluene, one of the BTEX (benzene, toluene, ethylbenzene, and xylene) compounds, is a clear, colorless liquid that becomes a vapor when exposed to air at room temperature. Toluene is typically used in a mixture with chemicals such as other solvents and paint pigments. Products that can contain toluene, such as paints, metal cleaners, and adhesives, are used in many industries. Gasoline and other fuels also contain toluene. The specific objective of this study was to investigate the toluene biodegradation efficiency in a freshly contaminated water by combined bioaugmentation and biostimulation processes and by natural attenuation. The term biostimulation is used to describe the addition of essential electron acceptors such as nutrients to enhance the microbial growth [9-11]. The term bioaugmentation is used to describe the addition of essential microorganisms. Several research studies have been conducted on the treatment of hydrocarbons by various microorganisms [12-18].

\section{Methodology}

\subsection{Configuration of PRBs}

Two reactors with the dimensions of $0.6 \mathrm{~m}$ height and 10 $\mathrm{cm}$ diameter are filled with coarse to medium sized sand. Each reactor column will have effluent port for water samples (Figure 1). The column reactors are operated as up flow. Reactor 1 (R-1) is inoculated with specific bacteria and required nutrients (N, P and K) are added. To maintain aerobic conditions, influent tank for reactor 1 is aerated as needed. Reactor 2 (R-2) is used as control and contains only sand and gravel but no bacteria and nutrients. No aeration is performed for reactor 2 .

For each reactor, $5 \mathrm{mg} / \mathrm{l}$ toluene concentration is prepared as influent sample. All the reactors are fed at an influent flowrate of $1 \mathrm{~mL} /$ minute.

\subsection{Reactive materials in PRBs}

The reactive filler material in the PRBs consists of the following mixed materials (Table 1). 


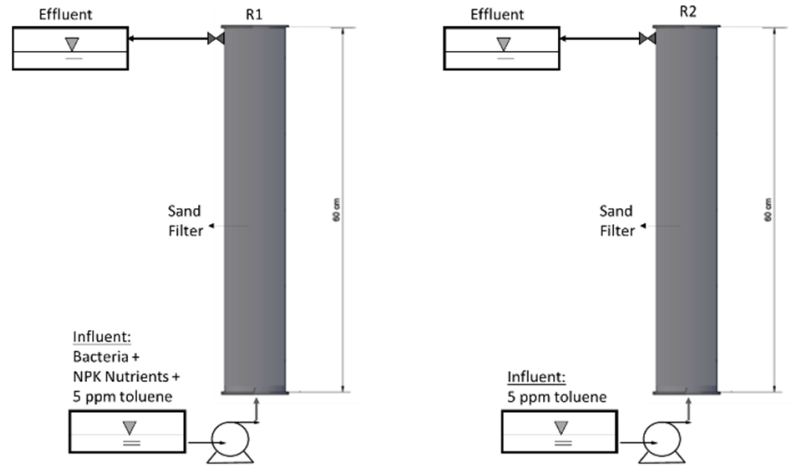

Fig. 1. The schematic of the PRB columns.

Table 1. Properties of filler material in PRBs.

\begin{tabular}{lccccc}
\hline Material & $\begin{array}{c}\text { Diameter } \\
(\mathrm{mm})\end{array}$ & $\begin{array}{c}\text { \% of } \\
\mathrm{SiO}_{2}\end{array}$ & $\begin{array}{c}\text { \% of acid } \\
\text { solubility }\end{array}$ & $\begin{array}{c}\text { Bulk } \\
\text { density } \\
\left(\mathrm{t} / \mathrm{m}^{3}\right)\end{array}$ & $\begin{array}{c}\text { Specific } \\
\text { gravity }\end{array}$ \\
\hline $\begin{array}{l}\text { Silica } \\
\text { sand }\end{array}$ & $1-2$ & $98 \pm 1$ & $1 \pm 0.5$ & $1.5-1.70$ & $2.55-2.70$ \\
$\begin{array}{l}\text { Silica } \\
\text { sand }\end{array}$ & $2-3$ & $98 \pm 1$ & $1 \pm 0.5$ & $1.5-1.70$ & $2.55-2.70$ \\
$\begin{array}{l}\text { Silica } \\
\text { sand }\end{array}$ & $3-6$ & $90 \pm 1$ & $10 \pm 0.5$ & $1.5-1.70$ & $2.55-2.70$ \\
$\begin{array}{l}\text { Silica } \\
\text { gravel }\end{array}$ & $8-12$ & $90 \pm 1$ & $10 \pm 0.5$ & $1.5-1.70$ & $2.55-2.70$ \\
\hline
\end{tabular}

\subsection{Analytical method}

An HPLC chromatograph equipped with a UV detector was used for toluene analysis. The UV detector was set to $254 \mathrm{~nm}$. The high-performance liquid chromatography column was a C18 Bond Pack $3 \mu \mathrm{m}(25 \mathrm{~cm}-4.6 \mathrm{~mm})$ analytical column. Chromatography was isocratic in a mobile phase composed of water-methanol (30-70). The flow rate was set at $1 \mathrm{ml} /$ minute. All chemicals and water used were HPLC grade.

\section{Results}

\subsection{Results of permeability tests}

Permeability is the water and air conductivity of the soil or sand. The falling head permeability test is a common laboratory test method used to determine the permeability of fine-grained soils with medium to low permeability such as sand, silt, and clay. Permeability of soils can be performed by using falling head and, constant head methods. In this study, falling head permeability test was performed by using the equation below:

where

$$
\mathrm{K}=\mathrm{a} \cdot \mathrm{L} / \mathrm{A} \cdot \mathrm{t} \cdot \ln \left(\mathrm{h}_{1} / \mathrm{h}_{2}\right)
$$

$\mathrm{K}=$ permeability in $\mathrm{cm} / \mathrm{sec}$

$\mathrm{a}=$ cross sectional area of the tube used for water elevation change $\left(\mathrm{cm}^{2}\right)$

$\mathrm{L}=$ length of the reactor $(\mathrm{cm})$

$\mathrm{A}=$ cross sectional area of the reactor $\left(\mathrm{cm}^{2}\right)$

$\mathrm{h}_{1}=$ distance of the water elevation to the bottom of the reactor before the test $(\mathrm{cm})$ $\mathrm{h}_{2}=$ distance of the water elevation to the bottom of the reactor after the test $(\mathrm{cm})$

\section{Reactor-1:}

$\mathrm{a}=\pi . \mathrm{r}^{2}=\pi .(5)^{2}=78.5 \mathrm{~cm}^{2}, \mathrm{~h}_{1}=70 \mathrm{~cm}, \mathrm{~h}_{2}=60 \mathrm{~cm}$, $\mathrm{t}_{\text {average }}=39.33 \mathrm{sec}, \mathrm{A}=78.5 \mathrm{~cm}^{2}, \mathrm{~L}=60 \mathrm{~cm}$

$\mathrm{K}=0.779 \mathrm{~cm} / \mathrm{sec}$

\section{Reactor-2:}

$\mathrm{a}=\pi \cdot \mathrm{r}^{2}=\pi .(5)^{2}=78.5 \mathrm{~cm}^{2}, \mathrm{~h}_{1}=70 \mathrm{~cm}, \mathrm{~h}_{2}=60 \mathrm{~cm}$, $\mathrm{t}_{\text {average }}=40 \mathrm{sec}, \mathrm{A}=78.5 \mathrm{~cm}^{2}, \mathrm{~L}=60 \mathrm{~cm}$

$\mathrm{K}=0.766 \mathrm{~cm} / \mathrm{sec}$

\subsection{Results of pore volume and porosity tests}

Pore volume and porosity tests are used to determine the volume and volume distribution of pores in sand filters on the apparent diameter of the pore inlets. In general, both the size and volume of pores affect the performance of sand filters. Therefore, the pore volume distribution is useful in understanding sand filter performance and determining a material that can be expected to perform in a particular manner.

Pore volume is the volume occupied by water in the reactor. To determine the pore volume, the reactor is filled with water and the amount of water was measured as pore volume.

\section{Reactor 1:}

Reactor volume $=\pi \cdot \mathrm{r}^{2} \cdot \mathrm{h}=3.14 \times(5)^{2} \times 60=4710 \mathrm{~cm}^{3}$

Pore volume $=1.06 \mathrm{~L}=1060 \mathrm{~cm}^{3}$

Porosity $(\varepsilon)=1060 / 4710=0.225$

\section{Reactor 2:}

Reactor volume $=\pi \cdot \mathrm{r}^{2} \cdot \mathrm{h}=3.14 \times(5)^{2}$ x $60=4710 \mathrm{~cm}^{3}$

Pore volume $=1.15 \mathrm{~L}=1150 \mathrm{~cm}^{3}$

Porosity $(\varepsilon)=1150 / 4710=0.244$

\subsection{Results of flow rate and hydraulic residence time tests}

The hydraulic residence time (HRT) (t) is a measure of the average time a soluble compound remains in a sand filter. In engineering, volumetric flow rate is the volume of fluid passing per unit of time; it is usually represented by the symbol Q.

Hydraulic residence time is the ratio of total water volume pumped to the flowrate as shown below.

\section{Reactor 1:}

$\mathrm{t}=\mathrm{V} / \mathrm{Q}$, where $\mathrm{V}=1.05$ liter $=1050 \mathrm{~mL}, \mathrm{Q}=1.2 \mathrm{~mL} /$ minute so $\mathrm{t}=1050 / 1.2=875$ minutes $=14.58 \mathrm{hrs}$.

\section{Reactor 2:}

$\mathrm{t}=\mathrm{V} / \mathrm{Q}$, where $\mathrm{V}=1.15$ liter $=1150 \mathrm{~mL}, \mathrm{Q}=1.2 \mathrm{~mL} /$ minute so $\mathrm{t}=1150 / 1.2=958.33$ minutes $=15.97 \mathrm{hrs}$. 


\subsection{Toluene removal in reactors}

Aromatic hydrocarbons such as BTEX compounds and their derivatives are among the most important contaminants of soil and groundwater. BTEX compounds are the most common groundwater pollutants among various petroleum hydrocarbons. BTEX compounds are released into the environment through spilled diesel fuel or gasoline and leaks from underground storage tanks and pipelines during transportation. BTEX compounds are listed as priority pollutants by the US Environmental Protection Agency and are among the top 100 chemicals on the hazardous substances' priority list. Therefore, the development or improvement of existing remediation methods that minimize the environmental damage caused by BTEX compounds has attracted the attention of environmental protection organizations. Biological treatment of contaminated groundwater is a wellestablished technique and is also known to be costeffective and environmentally friendly. During the biological degradation process, microorganisms can directly reduce BTEX to less toxic compounds by depleting the carbons present within the structure of BTEX. The performance of the biological treatment method is affected by various environmental factors such as temperature, oxygen, $\mathrm{pH}$ and inorganic nutrients. Therefore, these factors must be optimized for the implementation of efficient biological treatment systems. Bioremediation process in the PRBs has two main processes: a) Biostimulation - bioremediation process is enhanced by adding nutrients (NPK) and oxygen. b) bioaugmentation -microorganisms are added.

\subsection{Oxygen requirement}

For toluene $\left(\mathrm{C}_{6} \mathrm{H}_{6}\right)$, the biodegradation reaction will take place as follows:

$$
\mathrm{C}_{7} \mathrm{H}_{8}+9 \mathrm{O}_{2} \rightarrow 7 \mathrm{CO}_{2}+4 \mathrm{H}_{2} \mathrm{O}
$$

So, 1 mole of toluene requires 9 moles of oxygen. Since the total concentration of toluene is $5 \mathrm{ppm}(5 \mathrm{mg} / \mathrm{l})$, then the amount of oxygen required can be calculated as follows:

Molecular weight of toluene is $92 \mathrm{~g}$. If $92 \mathrm{~g}$ of toluene requires $9 \times 32=288 \mathrm{~g}$ oxygen, then $5 \mathrm{mg}$ toluene requires $0.0156 \mathrm{~g}$ oxygen. The required oxygen is provided by ambient air through aeration for R-1, but R-2 was not aerated since it is used as control.

\subsection{Nutrient requirement}

Molecular weight of toluene is $92 \mathrm{~g}$ and 1 mole of toluene contains $84 \mathrm{~g}$ of carbon (C) per mole of toluene. If $92 \mathrm{~g}$ of toluene contains $84 \mathrm{~g}$ of $\mathrm{C}$, then $5 \mathrm{mg}$ of toluene contains approximately $0.00456 \mathrm{~g}$ of C. As a nutrient, mixture of ammonium chloride $\left(\mathrm{NH}_{4} \mathrm{Cl}\right)$ and potassium dihydrogen phosphate $\left(\mathrm{KH}_{2} \mathrm{PO}_{4}\right)$ as $\mathrm{N}$ and $\mathrm{P}$ sources, respectively, are used.

Based on the ratio of $\mathrm{C}: \mathrm{N}: \mathrm{P}$ of $100: 5: 1$; if $\mathrm{C}$ is $0.00456 \mathrm{~g}$, then $\mathrm{N}$ required is $0.000228 \mathrm{~g}$ and $\mathrm{P}$ required is $0.0000456 \mathrm{~g}$. If 1 mole of $\mathrm{NH}_{4} \mathrm{Cl}(53 \mathrm{~g})$ contains $23 \mathrm{~g}$ of $\mathrm{N}$, then $0.000525 \mathrm{~g}$ of $\mathrm{NH}_{4} \mathrm{Cl}$ contains $0.000228 \mathrm{~g}$ of $\mathrm{N}$, so the amount of $\mathrm{NH}_{4} \mathrm{Cl}$ required is $0.000228 \mathrm{~g}$. Similarly, 1 mole of $\mathrm{KH}_{2} \mathrm{PO}_{4}(136 \mathrm{~g})$ contains $39 \mathrm{~g}$ of $\mathrm{P}$, then $0.000159 \mathrm{~g}$ of $\mathrm{KH}_{2} \mathrm{PO}_{4}$ contains $0.0000456 \mathrm{~g}$ of $\mathrm{P}$, so the amount of $\mathrm{KH}_{2} \mathrm{PO}_{4}$ required is $0.0000456 \mathrm{~g}$.

In summary, to bioremediate $5 \mathrm{mg} / 1$ of toluene in R-1, $0.000525 \mathrm{~g}$ of $\mathrm{NH}_{4} \mathrm{Cl}$ and $0.000159 \mathrm{~g}$ of $\mathrm{KH}_{2} \mathrm{PO}_{4}$ are required.

\subsection{Bacteria requirement}

To accelerate the biodegradation process in $\mathrm{R}-1$, one of the commercially available BTEX biodegrading bacteria such as Alcanivorax $s p$. is added to the system as inoculant.

\subsection{Toluene removal results}

Toluene removal rates for R-1 and R-2 are depicted in Figure 2. Toluene concentration in the influent sample for both reactors were $5 \mathrm{mg} / \mathrm{l}$. After 44 days of treatment, toluene concentrations were decreased from $5 \mathrm{mg} / \mathrm{l}$ to $4.304 \mathrm{mg} / \mathrm{l}$ by the natural attenuation treatment (R-1), which represents a $13.9 \%$ removal efficiency. Toluene was reduced to $0.0239 \mathrm{mg} / \mathrm{l}$ in the biostimulation and bioaugmentation treatment (R-1), which represents a toluene removal efficiency of $99.5 \%$. The efficiency of biodegradation was the highest when the BS and BA processes were combined.

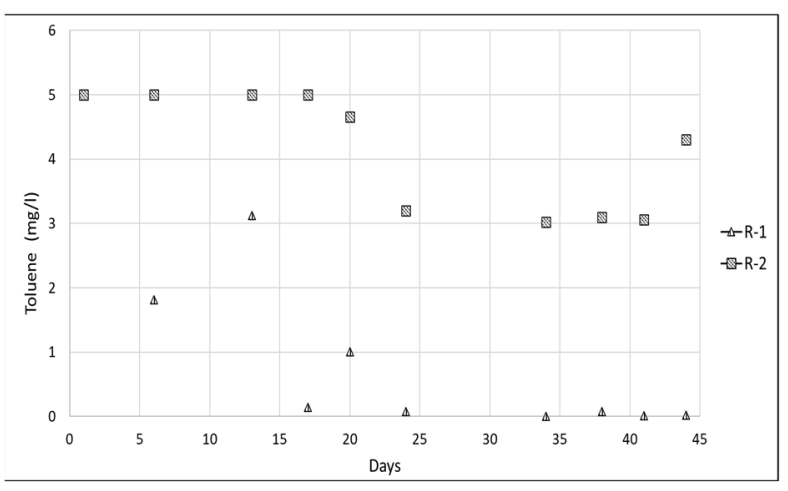

Fig. 2. Toluene removal rates in reactors.

\section{Discussion}

Bioaugmentation alone may not be effective to improve the remediation of hydrocarbon contaminated soils. Some research studies showed that bioaugmentation improves biodegradation efficiencies temporarily and that biostimulation seems to be a more preferred bioremediation technology to reach sufficient clean-up. Microbial populations are important in the remediation of petroleum hydrocarbon. Molecular methodologies provide help to understand the microbial community structure in remediation systems. Petroleum derived contaminants remaining in soil and groundwater for a long time after contamination along with costly treatment methods have made them one of the most important environmental pollutants. Improvement of hydrocarbon biodegradation is possible by applying different 
bioremediation technologies such as bioaugmentation and biostimulation alone or in combination. Biostimulation seems to be a more effective remediation methodology for BTEX removal than bioaugmentation alone.

Results of this study showed that combining BS and BA has a higher effect on biodegradation efficiency than NA process. Adding nitrogen and phosphorus, along with microbial inoculation and aeration can create an optimum condition for microorganisms to degrade toluene. This study assessed the effectiveness of bioaugmentation combined with biostimulation process on a freshly toluene-contaminated water. The results of this work justified that the bioaugmentation and biostimulation combined provided the accelerated biodegradation of toluene from the contaminated water through increased microbial biomass. Several different bacterial species would be needed to effectively biodegrade hydrocarbons. Single microbial species do not have the capacity to biodegrade more than two different compounds that are usually present in hydrocarbons. Conventionally, the higher the hydrocarbon degrading microbial population, the more hydrocarbon biodegradation takes place.

\section{Conclusions}

Petroleum hydrocarbons remaining in water for a long time after contamination along with costly treatment methods have made them one of the most important environmental pollutants. This study confirmed that it is possible to enhance the biodegradation of toluene in water by using different treatment methods such as bioaugmentation and biostimulation in combination. Analysis of toluene indicated that bioremediation of toluene contaminated water is very successful especially when BS and BA treatment are used together. In this study, the toluene degradation in the contaminated water was improved by bioaugmentation with genus Alcanivorax and biostimulation with nitrogen and phosphorus. The study also showed that bioaugmentation and biostimulation resulted in effective toluene removal within 44 days of treatment. The study highlighted the importance of in-situ groundwater treatment combined with bioaugmentation and biostimulation as a suitable strategy.

This research was funded by Imam Abdulrahman bin Faisal University (IAU) project No. (2019-037-Eng) throughout the Deanship of Scientific Research (DSR).

\section{References}

1. R. Thiruvenkatachari, \& S. Vigneswaran, R. Naidu, Permeable Reactive Barrier for Groundwater Remediation, J Ind Eng Chem. 14, 145-156 (2008).

2. EPA. Ground Water Currents, Issue No. 35. (2000)

3. M. Capodici, C. Morici, G. Viviani, Batch test evaluation of four organic substrates suitable for biological groundwater denitrification, Chemical Engineering Transactions, 38, 43-48 (2014).
4. C. Liu, X. Chen, E. Mack, S. Wang, W. Du, Y. Yin, S. Banwart, H. Guo, Evaluating a novel permeable reactive bio-barrier to remediate $\mathrm{PAH}$-contaminated groundwater, Journal of Hazardous Materials. 368, 444-451 (2019).

5. C. Fan, Y. Gao, Y. Zhang, Remediation of lead and cadmium from simulated groundwater in loess region in northwestern China using permeable reactive barrier filled with environmentally friendly mixed adsorbents. Environ Sci Pollut Res 25, 1486-1496 (2018).

6. F. Paulo R., N. Luiza, S. Sara V., M. Regina F.P.M., L. Mônica M.D., A. Camila C, Feasibility study of the use of basic oxygen furnace sludge in a permeable reactive barrier, Journal of Hazardous Materials, 351, 188-195, (2018).

7. J. Dong, Y. Zhao, W. Zhang, M. Hong, Laboratory study on sequenced permeable reactive barrier remediation for landfill leachate-contaminated groundwater, Journal of Hazardous Materials, 161, Issue 1, 224-230 (2009).

8. D. Zhou, Y. Li, Y. Zhang, C. Zhang, X. Li, Z. Chen, J. Huang, X. Li, G. Flores, M. Kamon, Column testbased optimization of the permeable reactive barrier (PRB) technique for remediating groundwater contaminated by landfill leachates, Journal of Contaminant Hydrology, 168, 1-16, (2014).

9. K. Yu, A. Wong, K. Yau, Y. Wong, N.F. Tam, Natural attenuation, biostimulation and bioaugmentation on biodegradation of polycyclic aromatic hydrocarbons (PAHs) in mangrove sediments, Mar. Pollut. Bull., 51, 1071-1077 (2005).

10. S. Kauppi, Sinkkonen, A. Romantschuk, Enhancing bioremediation of diesel-fuel-contaminated soil in a boreal climate: Comparison of biostimulation and bioaugmentation, Int. Biodeterior. Biodegrad, 65, 359-368, (2011).

11. T. Sayara, E. Borràs, G. Caminal, M. Sarrà, A. Sánchez, Bioremediation of PAHs-contaminated soil through composting: Influence of bioaugmentation and biostimulation on contaminant biodegradation, Int. Biodeterior. Biodegrad, 65, 859-865 (2011).

12. Y.M. Polyak, L.G. Bakina, M.V. Chugunova, N.V. Mayachkina, A.O. Gerasimov, V. Bure, Effect of remediation strategies on biological activity of oilcontaminated soil - A field study, Int. Biodeterior. Biodegrad, 126, 57-68, (2018).

13. Y. Jiang, K.J. Brassington, G. Prpich, G.I. Paton, K.T. Semple, S.J. Pollard, F. Coulon, Insights into the biodegradation of weathered hydrocarbons in contaminated soils by bioaugmentation and nutrient stimulation, Chemosphere, 161, 300-307, (2016)

14. K. Ramadass, M. Megharaj, K. Venkateswarlu, R. Naidu, Bioavailability of weathered hydrocarbons in engine oil-contaminated soil: Impact of bioaugmentation mediated by pseudomonas spp. on bioremediation, Sci. Total. Environ, 636, 968-974, 2018. 
15. M.S. Safdari, H.R. Kariminia, M. Rahmati, F. Fazlollahi, A. Polasko, S. Mahendra, W.V. Wilding, T.H. Fletcher, Development of bioreactors for comparative Study of natural attenuation, biostimulation, and bioaugmentation of petroleumhydrocarbon contaminated Soil, J. Hazard Mater, 342, 270-278, (2018)

16. M. Wu, X. Ye, K. Chen, W. Li, J. Yuan, X. Jiang, Bacterial community shift and hydrocarbon transformation during bioremediation of short-term petroleum-contaminated soil, Environ. Pollut, 223, 657-664, (2017).

17. M. Wu, W.A. Dick, W. Li, X.C. Wang, Q. Yang, T. Wang, L. Xu, M. Zhang, L. Chen, Bioaugmentation and biostimulation of hydrocarbon degradation and the microbial community in a petroleumcontaminated soil, Int. Biodeterior. Biodegrad, 107, 158-164, (2016)

18. A.S. Nwankwegu, C.O. Onwosi, Bioremediation of gasoline contaminated agricultural soil by bioaugmentation, Environ. Technol. Innov, 7, 1-11, (2017) 